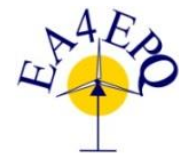

International Conference on Renewable Energies and Power Quality (ICREPQ'15) La Coruña (Spain), $25^{\text {th }}$ to $27^{\text {th }}$ March, 2015

Renewable Energy and Pourer Quality. Fournal (RE\&PQJ)

ISSN 2172-038 X, No.13, April 2015

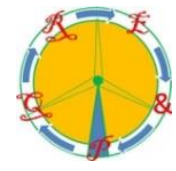

\title{
A First Approach on the Fault Impedance Impact on Voltage Sags Studies
}

\author{
A. C. L. Ramos ${ }^{1,4}$, A. J. Batista ${ }^{2}$, R. C. Leborgne ${ }^{3}$, E. G. Domingues ${ }^{4}$, W. P. Calixto ${ }^{1,4}$, A. J. Alves ${ }^{4}$. \\ ${ }^{1}$ Program in Electronic Systems and Automation, University of Brasilia, Brazil \\ e-mail: alessandro.clr@celg.com.br; wpcalixto@ieee.org \\ ${ }^{2}$ School of Electrical and Computer Engineering, Federal University of Goias \\ e-mail: batista@eee.ufg.br \\ ${ }^{3}$ Department of Electrical Engineering, Federal University of Rio Grande do Sul \\ e-mail: rcl@ece.ufrgs.br
}

\footnotetext{
${ }^{4}$ Nucleus of Studies Experimental and Technological, Electrotechnical Department - Federal Institute of Goias, Brazil e-mail: aja@ifg.edu.br; elder.domingues@ifg.edu.br
}

\begin{abstract}
An analysis of the fault impedance impact on studies of voltage sags caused by system faults is presented. The simulation of 62 case studies of phase-to-ground faults on 13.8, 69, 138 and $230 \mathrm{kV}$ transmission lines were performed and the voltage of a $380 \mathrm{~V}$ sensitive industrial busbar consumer was monitored. These lines are part of the electrical system of the city of Goiania, Brazil. For each case study, different fault positions were simulated by considering resistive fault impedances of $0,2,5,10,15 \Omega$ or a random fault impedance with a specific distribution function. Long-term simulation scenarios were obtained by the Monte Carlo method and analyzed based on their cumulative distribution functions and probability density curves of voltage sags. This is one major contribution of this work. We found that, the greater the fault impedance, the smaller the average number of voltage sags expected per year at the end-user busbar. However, the behavior of the average number of voltage sags of a given class of magnitude with the fault impedance does not follow a general law.
\end{abstract}

Index Terms-Power quality, voltage sag, fault impedance, Monte Carlo simulation.

\section{INTRODUCTION}

$\mathrm{S}$ "HORTduration undervoltages are called "voltage sags" or "voltage dips", the former term preferred by IEEE, and the latter by IEC. A voltage sag is defined as a sudden reduction on supply voltage magnitude followed by a voltage recovery after a short period of time. Specifically, the IEEE Std 11591995 [1] establishes the term "sag" to refer to a decrease of 0.1 p.u. to 0.9 p.u. in rms voltage, for a time period of 0.5 cycles to 1 minute. A voltage sag is characterized by its magnitude (the retained voltage), phase-angle jump, unbalance and duration [2]. Voltage sags are the main power quality disturbance that cause malfunction of sensitive loads [2-15]. Their causes include short-circuits, transformer energization, motor starting, and sudden load changes. However, shortcircuits are the cause of the most severe voltage sags in transmission and distribution networks [2].

There are many factors that influence voltage sags and some of them have received a considerable attention from the researchers as, for example: the fault characteristics (location [9], type [9], fault impedance [10] and fault distribution [11]), pre-fault voltage [12], fault rate [13], protection system [13], reclosing system [13] and the system generation level [15].

In general, the effect of the fault impedance in voltage sags and protection selectivity studies is ignored due to the lack of reliable information of the actual fault impedance and because only the most severe case is analyzed (zero fault impedance). Therefore, the voltage sag severity tends to be overestimated. The fault impedance effect is greater in distribution systems, due to the small short circuit capacity compared to transmission systems. Therefore the effect of the fault impedance on voltage sags magnitude tends to be larger at distribution systems [4], [5].

The representation of the fault impedance is a difficult subject since the fault arc varies with time and depends on the type of fault [16]. Besides that, the fault arc impedance also contributes to the total fault impedance when the fault is toground. The ground impedance also varies with time and depends on the fault location. For this reason, a constant impedance model is, in general, used [2]-[3]. In this paper, specific values of fault impedance magnitudes in the range of 0 to $15 \Omega$ are considered [10].

Due to the random nature of the faults and the transient process they can cause, voltage sag assessment may need to be performed by means of a stochastic method, using a time domain simulation tool [2]. Previous studies show that time and frequency domain simulations give similar results for voltage 
sag simulation, without missing significant information about the voltage sag magnitude [17].

A previous study showed the influence of fault impedance on the magnitudes of voltage sags caused by faults [9]. However, a prospective analysis, in probabilistic terms, for an individual consumer was not made. This work presents a research based on simulations, where the influence of fault impedance on the magnitudes and frequency distributions of voltage sags caused by faults, at a sensitive industrial busbar consumer, is analyzed. The software chosen for simulation is the ANAFAS [18], which is used by most of the Brazilian utilities to simulate faults in the frequency domain. Due to some limitations of this software, which will be described more ahead, a computational tool was implemented. This tool, named ANAFAS-GUI, permits, for example, to run several cases with different fault characteristics, including fault impedance. The simulation of 62 case studies were performed and the voltage of a industrial busbar consumer was monitored. For each case study, different fault positions were simulated by considering different resistive fault impedances (i.e., $0,2,5,10,15 \Omega$ or random). In order to manipulate the simulation results, another specific computational tool was implemented. This tool performs a Monte Carlo analysis, and treats data generated by ANAFAS-GUI for each value of fault impedance.

\section{THEORETICAL BACKGROUND}

Electrical faults are classified as three-phase faults (LLL), line-to-line faults (LL), three-phase line-to-ground faults (LLLG), two phase-to-ground faults (LLG) and line-to-ground faults (LG). The great majority of faults that occur in power systems are LG faults, reaching $75 \%$ as shown in Table I [2]. Therefore, in this paper, only LG faults are considered.

TABLE I

PROBABILITY OF OCCURRENCE OF FAULT TYPES.

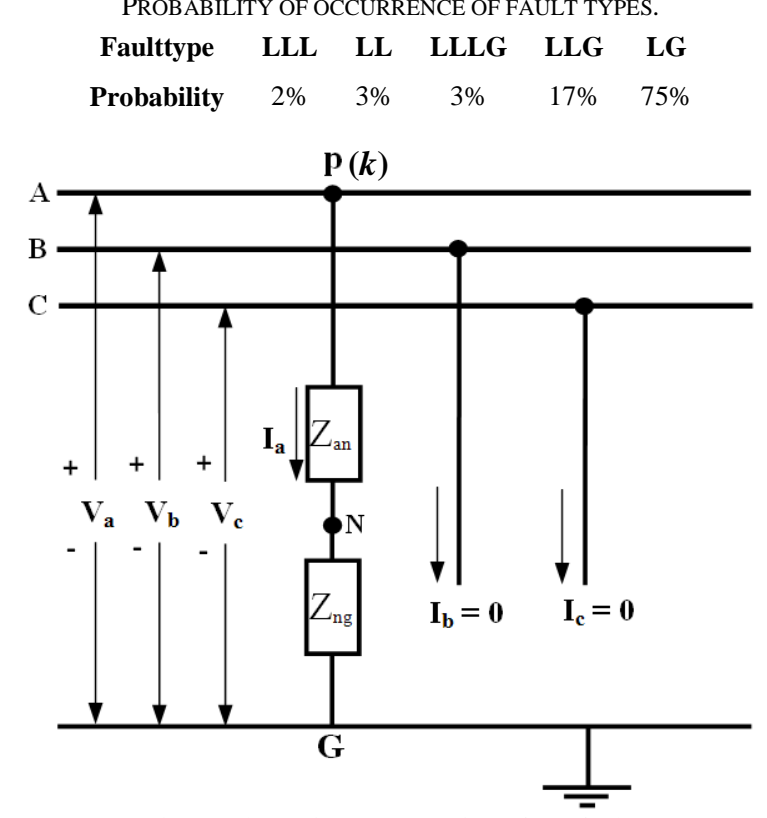

Fig. 1.Schematic representation of LG fault.

A schematic representation of the LG fault [18] is shown in Fig. 1.

A LG fault at busbar $k$ affects the voltage at busbar $i$. Using symmetrical components, the sequence voltages are calculated by (1) [19], [20].

$$
\left[\begin{array}{c}
E_{i, k}{ }^{0} \\
E_{i, k}{ }^{1} \\
E_{i, k}{ }^{2}
\end{array}\right]=\left[\begin{array}{c}
0 \\
E_{a i}{ }^{p r e f} \\
0
\end{array}\right]-\frac{E_{a k}{ }^{p r e f}}{Z_{k, k}+Z_{k, k}{ }^{2}+Z_{k, k}{ }^{0}+3\left(Z_{a n}+Z_{n g}\right)}\left[\begin{array}{c}
Z_{i, k}{ }^{0} \\
Z_{i, k}{ }^{1} \\
Z_{i, k}{ }^{2}
\end{array}\right] \text { (1) }
$$

The voltages of phases A, B and C at busbariare obtained by (2).

$$
\left[\begin{array}{c}
E_{a_{i, k}} \\
E_{b_{i, k}} \\
E_{c_{i, k}}
\end{array}\right]=\left[\begin{array}{ccc}
1 & 1 & 1 \\
1 & a^{2} & a \\
1 & a & a^{2}
\end{array}\right]\left[\begin{array}{l}
E_{i, k}{ }^{0} \\
E_{i, k}{ }^{1} \\
E_{i, k}^{2}
\end{array}\right]
$$

Where:

$$
\begin{aligned}
& E_{a i, k}, E_{b i, k}, E_{c i, k} \quad \text { voltages of phases A, B and C, respectively, } \\
& \text { at busbar } i \text { during LG fault at busbar } k \text {; } \\
& E_{i, k}{ }^{0}, E_{i, k}{ }^{l}, E_{i, k}^{2} \quad \text { zero, positive and negative sequence voltag- } \\
& \text { es, respectively, at busbar } i \text { during LG fault } \\
& \text { at busbar } k \text {; }
\end{aligned}
$$

According to (1) and (2) the magnitude of a voltage sag, due to a LG fault, depends on the following variables:

- Pre-fault voltage at monitoring busbar, $E_{i}^{\text {pref }}$;

- Pre-fault voltage at fault position, $E_{k}{ }^{\text {ref }}$;

- System self impedance, $Z_{k k}$; and

- System fault location, $Z_{i, k}$.

According to (1) the voltage sag magnitude also depends on the composition of the fault impedance $\left(Z_{a n}\right.$ and $\left.Z_{n g}\right)$. However this impedance is neglected in most voltage sag studies [16]. Therefore, this paper has the aim of showing the quantitative impact of the fault impedance on voltage sags.

\section{MethodOLOGY}

Voltage sag quantitative assessment can be performed by: (a) the number of voltage sags according to magnitude and duration classes; and (b) the probability density function according to the sag magnitude [21].

These studies are performed by measurement or by simulation [1]. The quantitative voltage sag study by measurement is often not feasible at large power systems due to the high costs of measuring equipment and the post-measurement engineering work [1], [21].

There are three main methods to simulate voltage sags: waveform simulation, dynamic simulation and fault simulation. Due to the characteristic of voltage sags treated in this paper, the work is based on the fault simulation method. This type of simulation can be performed by the software ANAFAS [18]. Previous studies show that this software can be readily used to simulate voltage sags with good accuracy [17]. However, this tool does not permit the interactive insertion of fault impedance during simulation. In order to overcome this limitation, a computational program, called ANAFAS-GUI, was developed. This tool allows the insertion of fault impedance by interactive windows.

ANAFAS software performs fault simulations in automatic 
and interactive modes. In automatic mode a $1 \%$ step can be used to locate the fault along any transmission line, but the fault impedance is always null. In interactive mode, the software permits, for a fixed fault position, to change the fault impedance. With the goal of eliminating these limitations and also to improve the performance by the execution of various ANAFAS simulations in "background", a software was implemented in JAVA language. The implemented software, named ANAFAS-GUI, permits to run simulations with different fault positions, short-circuit types, fault impedances and distributed generation levels at one or more system busbars.

The analyzed system has 62 transmission lines and 42 transformers, including end-user transformers. The system is shown in Fig. 2. The industrial busbar consumer monitored is described in the top of Fig. 2 as "Client C busbar 9112". The consumer transformers are included in the model. Shortcircuits are simulated in all lines of the grid. In each fault

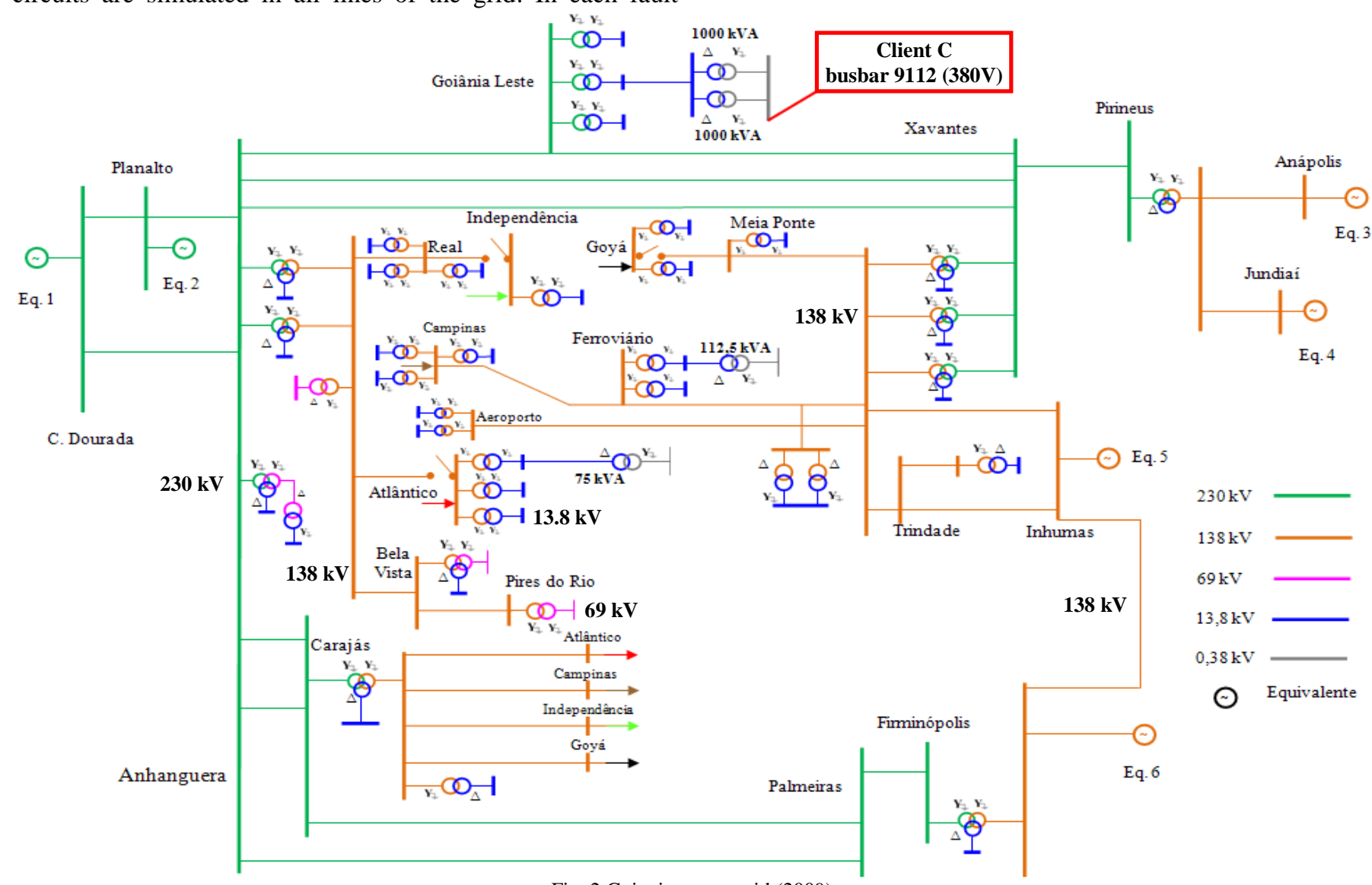

Fig. 2.Goiania power grid (2009).

transmission lines, according to voltage level, are shown in Table II. According to the fault rates per kilometer per year and the length of the lines, a total of 113 faults per year are simulated;

4. For each simulated year, the faulted line is chosen (FROM-busbar and TO-busbar): this number varies from 1 to 62 . Then, randomly choose a number that represents the location of the fault. For each year, this procedure is repeated 113 times, producing 113 recorded values of voltages at end-user's busbar. These values are lately filtered in order to select only those which represent voltage sag.

5. After item 4, the year is increased by 1 . If the number of study, the fault location ranges from zero to $100 \%$ in steps of $1 \%$ for every line. Also, for each fault position, resistive fault impedances of $0,2,510$ and $15 \Omega$ are considered. A second set of simulations considering a random impedance value was performed. For both studies a pre-fault voltage of 1 p.u. is always assumed.

In order to manipulate data from the simulation results, another specific computational tool was implemented in MATLAB. This tool performs a Monte Carlo analysis and treats data generated by ANAFAS-GUI for each fault impedance value. The Monte Carlo algorithm is described as follows:

1. Choose the busbar where the study is to be performed;

2. Choose the number of scenarios or years of simulation;

3. Previously obtain the number of faults on the system, according to the fault rate of each line. The fault rates of 


\section{Simulation Results}

Voltage sags are assessed in terms of frequency and magnitude. First, the number of voltage sags at one end-user bursars analyzed. These results are observed in tendency curves for a 1,000-year scenario. In a second approach, the average number of voltage sags according to the sag magnitude class is analyzed. Results are shown according to IEC 61000-2-8 [22].

Figs. 3 to 5 show the number of voltage sags obtained for the end-user busbar, considering only solid faults.In Fig. 3 the average number of voltage sags is calculated by:

$$
N_{\text {sag }}=\frac{1}{N_{\text {years }}} \sum_{i=1}^{N_{\text {years }}} X_{i}
$$

Where:

$N_{\text {sag }} \quad$ number of expected voltage sags;

$N_{\text {years }}$ number of years of simulation;

$X_{i} \quad$ number of voltage sags for a specific year.

The results give a general view of the performance of the end-user busbar, in terms of voltage sag frequency. For example, for an end-user with a sensitive equipment or process, the results can help in estimating per year costs. In this kind of analysis, it is necessary to know the sensitivity of the process, obtained from equipment manufacturers, according to sensitivity curves such as CBEMA or ITIC [1], [5], [14].In order to consider the time as a variable in the adopted methodology it would be necessary the adjustment of the each line protections.

Curves in Figs. 3 to 5 show that, for 1,000 Monte Carlo simulations (SMC), the average number of voltage sags for the end-user is 67. Fig. 3 shows that there is a large variation in the number of expected sags between years, however, in the long term the average value converges fast. Fig. 4 shows that the maximum number of voltage sags (bar graph) coincides with the same average value.

The frequency of voltage sags according to sag magnitude classes can be assessed by Fig. 5. It can be seen that the enduser has a greater number of voltage sags in the classes of 0.70 to 0.85 p.u. and of 0.85 to 0.9 p.u.. The number of voltage sags in the class of 0.50 to 0.70 p.u. is slightly lesser. Fig. 5 also shows that the busbar 9112 has a very low probability of voltage sags in the class of 0.10 to 0.50 p.u., when solid faults are simulated.

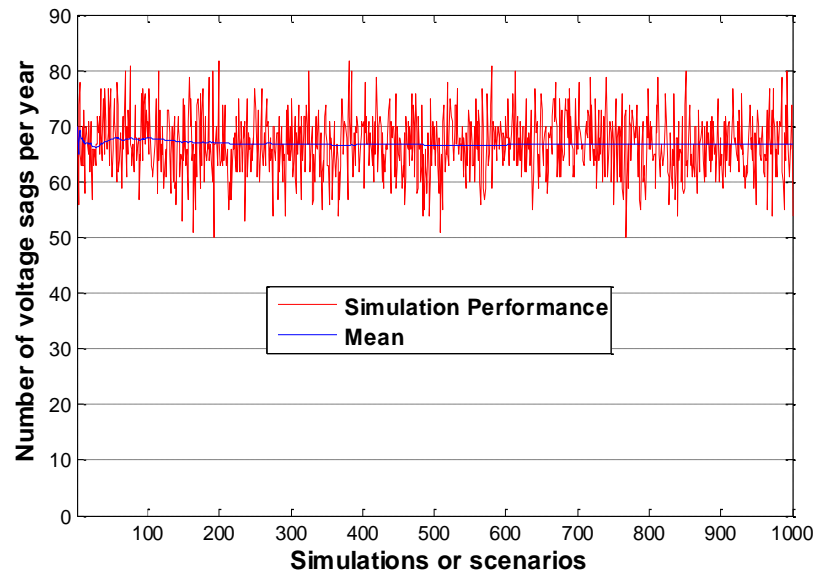

Fig. 3. Performance of the simulation and estimation of the average number of voltage sags at busbar 9112 for 1,000 years, for a fault impedance of 0 (zero) $\Omega$.

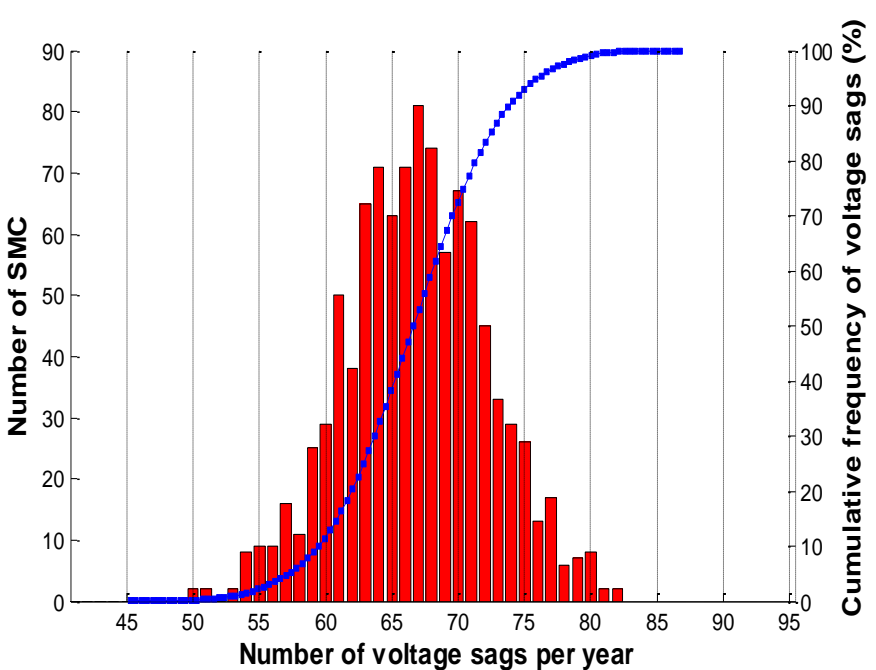

Fig. 4. Frequency and cummulative distribution of voltage sags at busbar 9112 for 1,000 years, for a fault impedance of 0 (zero) $\Omega$.

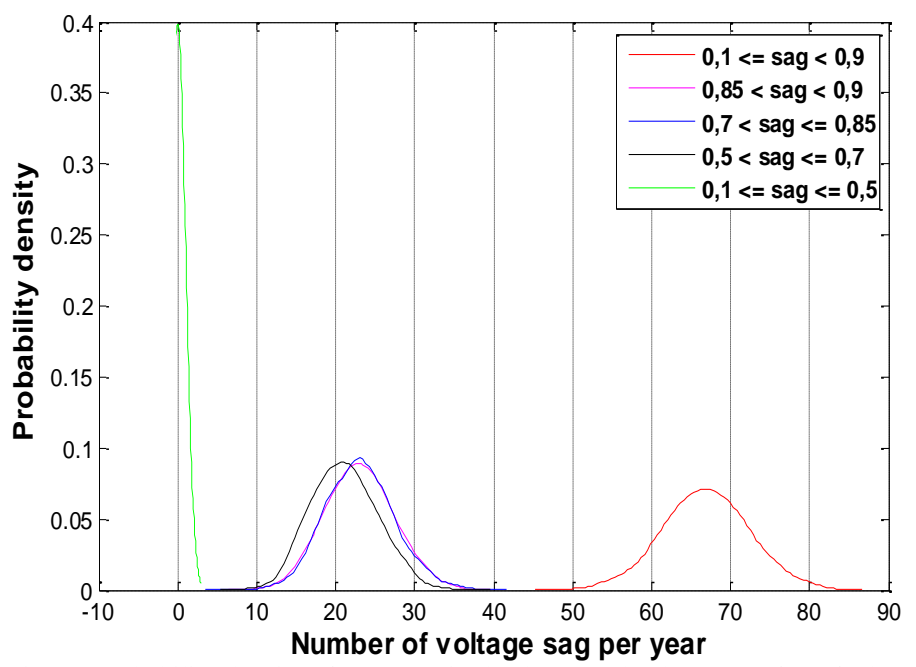

Fig. 5. Probability density of sag magnitude classes at busbar 9112, for a fault impedance of 0 (zero) $\Omega$.

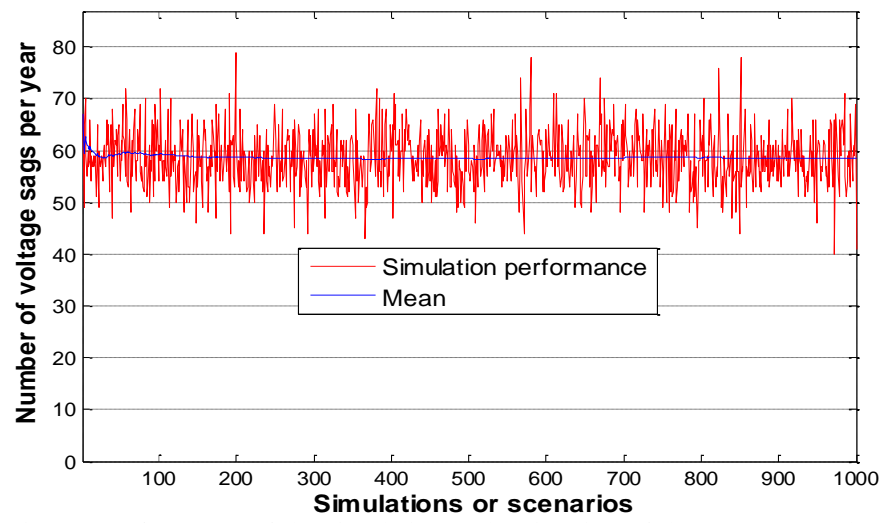

Fig. 6. Performance of the simulation and estimation of the average number of voltage sags at busbar 9112 for 1,000 years, for a random fault impedance.

According to the second set of simulations, where the fault impedance was a random variable, the number of average voltage sags falls to 59, as shown in Figs. 6-8. Fig. 8 shows a small increase in the number of voltage sags in the class of 0.10 to 0.50 p.u.. However, the number of voltage sags in the other classes diminished, mostly those voltage sags in the class of 0.50 to 0.70 p.u.. 


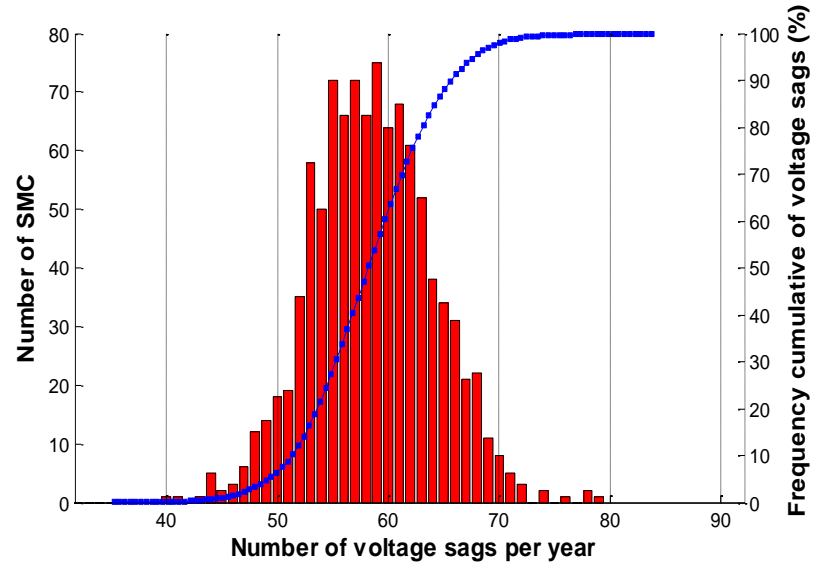

Fig. 7. Frequency and cummulative distribution of voltage sags at busbar 9112 for 1,000 years, for a random fault impedance.

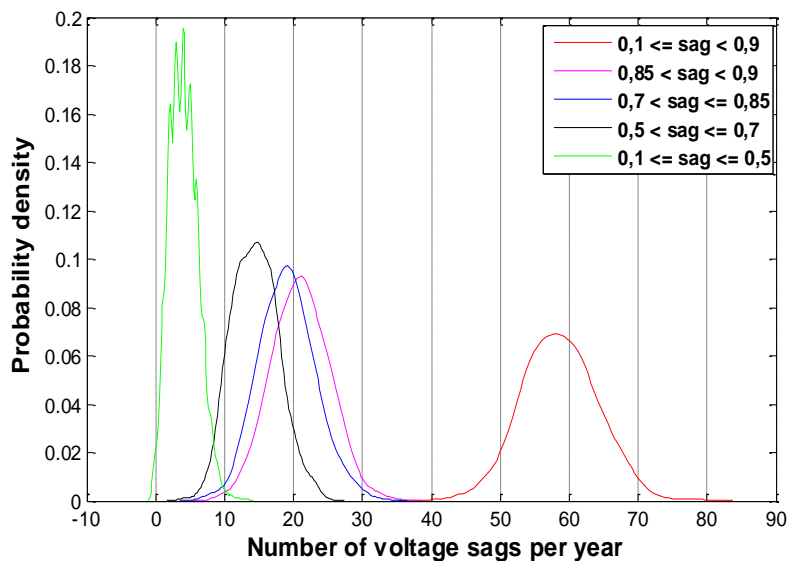

Fig. 8. Probability density of sag magnitude classes at busbar 9112, for a random fault impedance.

According to Figs. 9 to 11 , where a large fault impedance is simulated $(15 \Omega)$, the average number of voltage sags falls to 35. Fig. 9 shows that the variability of the expected number of sags does not change compared with the previous set of simulations. Fig. 10 shows that the most common number of sags is 36 , although the average number of sags is 35 . Fig. 11 shows that the number of sags in the class of 0.1 to 0.5 p.u. is similar to the number of sags obtained in the set of simulation with $0 \Omega$. Fig. 11 shows also that the difference between the sag magnitude classes is larger than in the previous sets of simulations.

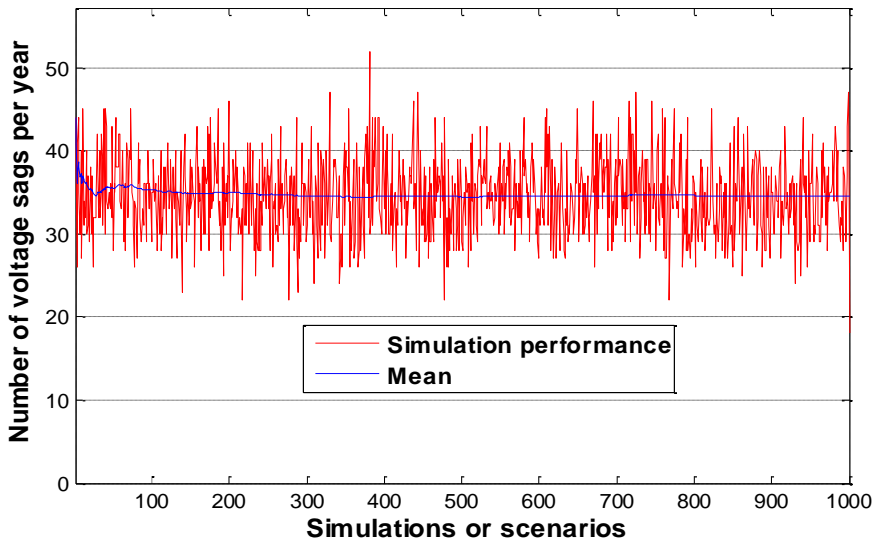

Fig. 9. Performance of the simulation and calculus of average number of voltage sags at busbar 9112 for 1,000 years, for a fault impedance of $15 \Omega$.

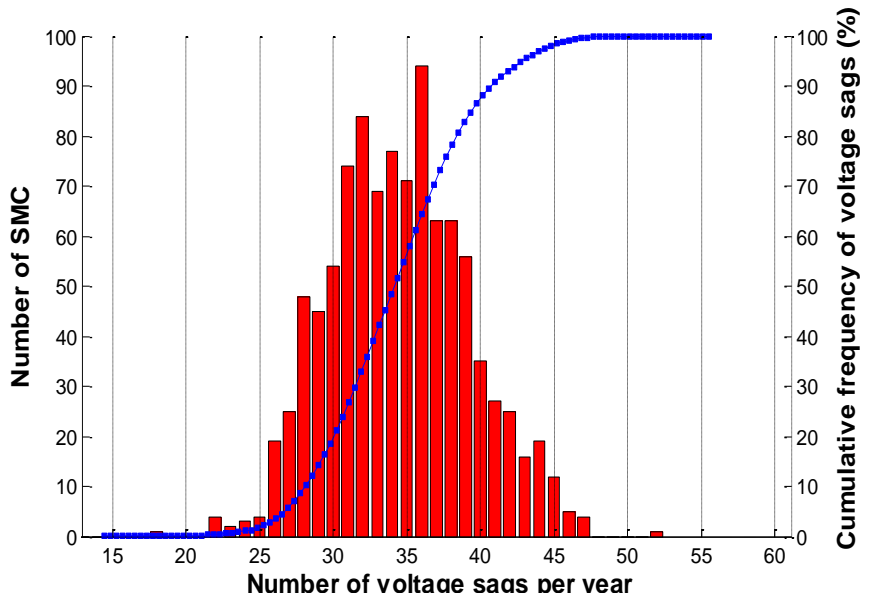

Fig. 10. Frequency and cummulative distribution of voltage sags at busbar 9112 for 1,000 years, for a fault impedance of $15 \Omega$.

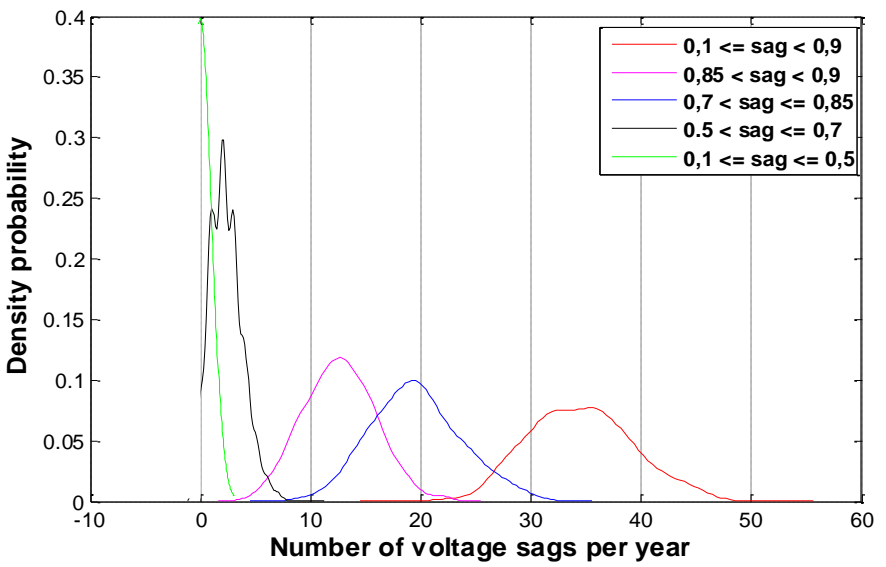

Fig. 11. Probability density of sag magnitude classes at busbar 9112, for a fault impedance of $15 \Omega$.

TABLE III

AVERAGE NUMBER OF VOLTAGE SAGS ACCORDING TO VOLTAGE CLASS AND FAULT IMPEDANCE AT BUSBAR 9112.

\begin{tabular}{c|c|c|c|c|c}
\multirow{2}{*}{$\begin{array}{c}\text { Fault } \\
\text { impedance } \\
(\boldsymbol{\Omega})\end{array}$} & \multicolumn{5}{|c}{ Sag magnitude classes (p.u.) } \\
\cline { 2 - 6 } & $\mathbf{0 . 1 - 0 . 5}$ & $\mathbf{0 . 5}-\mathbf{0 . 7}$ & $\mathbf{0 . 7}-\mathbf{0 . 8 5}$ & $\mathbf{0 . 8 5} \mathbf{- 0 . 9}$ & $\mathbf{0 . 1} \mathbf{- 0 . 9}$ \\
\hline $\mathbf{0}$ & 0 & 21.0 & 23.0 & 23.0 & 66.8 \\
\hline Random & 4.1 & 14.4 & 19.1 & 21.1 & 58.6 \\
\hline $\mathbf{2}$ & 5.1 & 14.7 & 20.3 & 20.5 & 60.5 \\
\hline $\mathbf{5}$ & 5.3 & 14.0 & 18.6 & 22.0 & 59.9 \\
\hline $\mathbf{1 0}$ & 0 & 16.6 & 9.3 & 26.1 & 52.0 \\
\hline $\mathbf{1 5}$ & 0 & 2.3 & 19.6 & 12.6 & 34.5 \\
\hline
\end{tabular}

TABLE IV

RELATIVE VARIATION OF VOLTAGE SAGS AT BUSBAR 9112 FOR 0 (ZERO) AND $15 \Omega$ FAULT IMPEDANCES.

$\begin{array}{cccccc}\text { Sag magnitude } & \mathbf{0 . 1 - 0 . 5} & \mathbf{0 . 5 - 0 . 7} & \mathbf{0 . 7 - 0 . 8 5} & \mathbf{0 . 8 5 - 0 . 9} & \mathbf{0 . 1 - 0 . 9} \\ \text { classes (p.u.) } & 0 & -88 & -15 & -45 & -48\end{array}$

Finally, the effect of the fault impedance on voltage sags at the monitored end-user busbars summarized in Table III. This table shows the average frequency of voltage sags for each magnitude class. Also it is seen that the increase of the fault impedance leads to a considerable decrease of the voltage sags 
frequency (class of 0.1 to 0.9 p.u.). That cannot be concluded to the most severe voltage sags (class of 0.1 to 0.5 p.u.), where the sag frequency does not reduce with the increase of fault impedance.

In order to quantify the variation of voltage sag frequency for each sag magnitude class due to the fault impedance, the percent relative variation is calculated by (4). The fault impedances for this calculation are 0 (zero) and $15 \Omega$. The results are shown in Table IV. According to this table, it can be concluded that: (a) the number of voltage sags in the class of 0.1 0.5 p.u. does not change; (b) the number of voltage sags in the class of 0.5-0.7 p.u. decreases $88 \%$; (c) the number of voltage sags in the class of 0.7-0.85 p.u. decreases $15 \%$; (d) the number of voltage sags in the class of $0.85-0.90$ p.u. decreases 45 $\%$; and (e) in general, the number of voltage sags decreases 48 $\%$.

$$
\Delta N_{\text {sag }}=\left(\frac{N_{\text {sag }, 15 \Omega}-N_{\text {sag }, 0 \Omega}}{N_{\text {sag }, 0 \Omega}}\right) \cdot 100
$$

Where:

$\Delta N_{\text {sag }} \quad$ percent variation of voltage sag frequency;

$N_{\text {sag, } 0 \Omega}$ number of voltage sags for $0 \Omega$ fault impedance;

$N_{\text {sag, } 15 \Omega}$ number of voltage sags for $15 \Omega$ fault impedance.

\section{CONCLUSION}

This paper shows the effect of the fault impedance in voltage sags assessment. Quantitative studies were performed at an end-user busbar. The fault impedance was considered to be random, 0 (zero), 2, 5, 10, and $15 \Omega$.

A scenario of 1,000 years was considered in order to verify the tendency of voltage sags. Probability density and cumulative frequency curves were analyzed. We observed that, the greater the fault impedance, the smaller the average number of voltage sags expected per year at the end-user busbar. However, the behavior of the average number of voltage sags of a given class of magnitude with the fault impedance does not follow a general law. Therefore, if the fault impedance is modeled as a random variable, the obtained results are more probable to occur.

\section{ACKNOWLEGMENT}

The authors thank CELG Generation and Transmission S.A - CELG GT, that has allowed them to use the software ANAFAS in the simulations. The author thanks the financial support the CELG GT.

\section{REFERENCES}

[1] IEEE Recommended practice for monitoring electric Power quality, IEEE Standard 1159-1995.

[2] J. A. Martinez, J. M.Arnedo, "Voltage Sag Studies in Distribution Networks - Part II: Voltage Sag Assessment," IEEE Transactions on Power Delivery, vol. 21, no. 3, 2006, pp. 1679-1688.

[3] J. A. Martinez, J. M.Arnedo, "Voltage Sag Stochastic Prediction Using an Eletromagnetic Transient Program," IEEE Transactions on Power Delivery, vol. 19, no. 4, 2004, pp. 1975-1982.

[4] R. C. Degeneff et.al, "Reduzing the Effect of Sags and Momentary Interruptions: A Total Owning Cost Prospective," In Proc. 9th International Conference on Harmonics and Quality of Power, vol. 2, 2000, pp. 397-403.

[5] J. C. Cebrian, N. Kagan, "Hybrid Method to Assess Sensitive Process Interruption Costs Due to Faults in Electric Power Distribution Networks", IEEE Transactions on Power Delivery, vol. 25, pp. 1686 -
1696, 2010.

[6] M. H. J. Bollen, Understanding Power Quality Problems:Voltage Sags and Interruptions, McGraw-Hill, IEEE Press Series on Power Engineering, 2000.

[7] R. C. Leborgne, "Voltage Sags Characterization and Estimation". Thesis for the degree of Licentiate of Engineering, Chalmers University of Technology, 2005.

[8] Voltage Characteristics in Public Distribution Systems, European Standard, CENELEC EN 50160, 2007.

[9] M. N. Moschakis, N. D. Hatziargyriou, "Analytical Calculation and Stochastic Assessment of Voltage Sags," IEEE Transactions on Power Delivery, vol. 21, no. 3, 2006, pp. 1727-1734.

[10] J. A. Martinez, J. M.Arnedo, "Voltage Sag Stochastic Prediction Using an Eletromagnetic Transient Program," IEEE Transactions on Power Delivery, vol. 19, no.4, 2004, pp. 1975-1982.

[11] J. V. Milanovic, M. T.Aung, C. P. Gupta. "The Influency Of Fault Distribution on Stochastic Prediction of Voltage Sags," IEEE Transactions on Power Delivery, vol. 20, no. 1, 2005.

[12] J. V. Milanovic, R. Gnativ, K. W. M. Chow, "The Influence Of Loading Conditions And Networks Topology On Voltage Sags," In Proc. 9th International Conference on Harmonics and Quality of Power, vol. 2, 2000, pp. 757-762.

[13] Y. S. Lim, G.Strbac, "Analytical Approach to Probabilistic Prediction of Voltage Sags on Transmission Networks,"IEE Proc. Generation Transmission and Distribution, vol. 149, 2002, pp. 7-14.

[14] J. A. M. Velasco, J. M. Arnedo, "Voltage Sag Studies in Distribution Networks - Part II: Voltage Sag Assessment," IEEE Transactions on Power Delivery, vol. 21, no. 3, 2006, pp. 1679-1688.

[15] J. A. M. Velasco, J. M. Arnedo, "Distributed Generation Impact on Voltage Sags in Distributions Networks," In Proc. 9th International Conference on Electrical Power Quality and Utilization, 2007, pp. 1-6.

[16] S. H. Horowitz, A. G. Phadke, Power System Relaying, 3rd ed., John Wiley \& Sons, 1992.

[17] J. M. C. Filho et.al, "Validation of voltage sag simulation tools: ATP and short-circuit calculation versus field measurements," IEEE Transactions on Power Delivery, vol. 23, no. 3, 2008, pp. 1472-1480.

[18] Research Center of Energy - CEPEL User's Program Analysis Simultaneous Faults - ANAFAS, v. 4.4, Rio de Janeiro, Brazil, 2007.

[19] W. D. Stevenson Jr., Elements of Power System Analysis, 4th ed. McGraw-Hill, 1982.

[20] P. M. Anderson, Analysis of Faulted Power Systems, John Wiley \& Sons, IEEE Press Series on Power Engineering, 1995.

[21] G. Olguin, D. Karlsson, R. C. Leborgne, "Stochastic Assessment of Voltage Sags (Dips): The Method of Fault Positions versus a Monte Carlo Simulation Approach," In IEEE Power Tech, 2005, pp. 1-7.

[22] Electromagnetic Compatibility (EMC) - Part 2: Environment - Section 6: Voltage Dips and short interruptions on public electric power supply systems with statistical measurements results, IEC 61000-2-8, 2002. 